\title{
Avaliação da qualidade ambiental através do teste da cebola (Allium cepa L.) Exposta diretamente em leito de rios urbanos
}

\author{
Evaluation of environmental quality by Allium test (Allium cepa L.) directly exposed in urban streams \\ bed \\ Marcelo Netto Duarte, Marcos Antônio de Araújo Nogueira, Cleber José Fermiano Paschoal, Alan \\ Gomes Miranda, Geneci Leme Monsores, Luiz Alves da Costa, Enilson Salino Braga, Bárbara Barbosa \\ Braga, William Costa Rodrigues.
}

\begin{abstract}
Resumo
O presente estudo teve como objetivo avaliar a qualidade ambiental de rios urbanos através do teste da cebola (Allium cepa L.) exposta diretamente no leito dos rios do município de Vassouras-RJ. O experimento teve quatro tratamentos, no Rio Bonito, Rio Santa Catarina e Rio das Mortes e na confluência dos três, e como testemunha, um lago próximo a uma nascente. Foram utilizadas cinco estruturas de isopor que permite as cebolas flutuar na água. Durante o experimento, ocorreu uma enxurrada que fez perdermos três experimentos, restando apenas a testemunha e o do Rio Bonito. Após sete dias, os experimentos restantes foram desmontados e mediu-se a massa e o comprimento das raízes. Os resultados obtidos entre o tratamento e a testemunha foram estatisticamente significativo, através do teste t-student $(\mathrm{p}<0,05)$, tanto no comprimento das raízes quanto na massa, assim podendo-se concluir que há compostos químicos que inibiram o crescimento normal das raízes no Rio Bonito e que, apesar de possíveis erros na metodologia, os resultados corroboram outros estudos com ensaios em laboratório. Palavras-chave: Bioensaio. Genotoxicidade. Bioindicador.
\end{abstract}

Como citar esse artigo. Duarte MN, Nogueira MAA, Paschoal CJF, Miranda AG, Monsores GL, Costa LA, Braga ES, Braga BB, Rodrigues WC. Avaliação da qualidade ambiental através do teste da cebola (Allium cepa L.) Exposta diretamente em leito de rios urbanos. Revista Teccen. 2014 Jan./Dez.; 07 (1/2): 05-10.

\begin{abstract}
The present study aimed to evaluate the environmental quality of urban rivers by the Allium test (Allium cepa L.) exposed directly in streams bed of the municipality of Vassouras-RJ. The experiment had four treatments, in the River Bonito, River Santa Catarina, River das Mortes, and in the confluence of the three, and as control, a lake near than a source. Styrofoam structures were used to allow the onion float over the water. During of the experiment, occurred a flood that did we lost three experiments, remaining only the control and the Bonito river. After seven days, the remaining experiments were dismantled and measured the weight and length of the roots. The results obtained between the treatment and the control were statistically significant, by the student's t-test $(\mathrm{p}<0,05)$, in both the length of the roots as the weight, thus we conclude that there are chemicals compounds that inhibited the normal growth of roots in the Bonito river, and despite the possible errors in the methodology, the results corroborate other studies with assays in the laboratory. Keywords: Bioassay. Genotoxicity. Bioindicator.
\end{abstract}

\section{Introdução}

A cidade de Vassouras começou a ser povoada em 1816. Durante muito tempo foi considerada o núcleo da aristocracia real fluminense principalmente pelo grande volume da produção cafeeira da época, mais com a abolição da escravatura em 1888, ocasionou a perda da sua principal mão de obra, levando assim ao abandono de terras e da cultura de café, estando atualmente quase eliminada nesta região (IBGE 2010).

Historicamente o desenvolvimento urbano e industrial ocorreu ao longo dos rios devido à disponibilidade de água para abastecimento e a possibilidade de utilizar o rio como corpo receptor dos dejetos (Giordano 2004).

A água encontra-se disponível sob várias formas e é uma das substâncias mais comuns na natureza, cobrindo cerca de $70 \%$ da superfície terrestre. Todos os organismos necessitam de água para sobreviver e sua disponibilidade é um dos fatores para a manutenção dos ecossistemas, e para isso é fundamental que este recurso esteja dentro dos padrões de qualidade e isento de substâncias que possam causar efeitos deletérios aos organismos (Braga et al. 2005).

Atualmente, as atividades humanas têm ocasionado alterações significativas no meio ambiente, devido ao novo estilo de vida e a busca incessante pelo desenvolvimento, o que tem comprometido sua qualidade (Brasil, 2006). Os efluentes de diversas origens (industrial, doméstico, agrícola), que são, indiscriminadamente, liberados no meio ambiente, contêm substâncias com características mutagênicas, 
genotóxicas e citotóxicas, as quais são responsáveis pela poluição dos ecossistemas e, consequentemente, afetam a saúde humana (Barbério 2008).

A maioria das pessoas não tem conhecimento de que a qualidade das águas de cursos d'água está diretamente relacionada com a saúde delas. De todas as formas de contaminação, a mais citada e mais frequente em termos de quantidade é o lançamento de resíduos orgânicos oriundos dos esgotos domésticos ou industriais sem prévio tratamento (Valença 2003).

A degradação dos mananciais, proveniente do deflúvio superficial agrícola, têm causado impactos aos ecossistemas aquáticos, devido ao aumento dos níveis de nutrientes na água pode comprometer sua utilização para abastecimento doméstico, devido a alterações no sabor e odor da água ou à presença de toxinas liberadas pela floração de alguns tipos de algas. Além das implicações causadas pelos nutrientes aos recursos hídricos, é necessário considerar, também, a contribuição dos agroquímicos e dos metais pesados (Merten e Minella 2002).

A noção clássica de contaminação das águas, e de sua avaliação, envolve a determinação da presença e da concentração de substâncias potencialmente nocivas, baseada na identificação de poluentes específicos em pontos amostrais determinados, por meio de análises físicas, químicas e biológicas, o que fornece informações importantes o estado de integridade de rios (Bollmann e Edwiges 2008; Silveira 2004).

Os rios utilizados no estudo pertencem a bacia hidrográfica do Rio Paraíba do Sul, que segundo Barbério et al. (2009), é um rio que fornece geração de energia, abastecimento de água urbana, assimilação de resíduos urbanos, industriais e agrícolas, e de irrigação, entre muitos benefícios, para uma área extensa, recebendo assim diversos resíduos de origens difusas. Como muitos outros rios que recebem elementos supostamente tóxicos de seus efluentes, contribuíram por resíduos das indústrias, agricultura e esgoto doméstico, o Rio Paraíba do Sul, localizada no sudeste do Brasil, necessária assim a monitoramento de possíveis efeitos tóxicos de sua água (Barbério et al. 2009).

A Resolução CONAMA N $N^{\circ} 357 / 05$ define monitoramento como "medição ou verificação de parâmetros de qualidade e quantidade de água, que pode ser continua ou periódica, utilizada para acompanhamento da condição e controle da qualidade do corpo de água", além disso, "a qualidade dos ambientes aquáticos poderá ser avaliada por indicadores biológicos, utilizando-se organismos e/ou comunidades aquáticas" (CONAMA 2005).

Devido à complexidade e variabilidade de compostos orgânicos e inorgânicos que podem estar presentes num mesmo efluente ou corpo hídrico, é recomendável que a caracterização dessas águas seja complementada com ensaios biológicos. Dentre os métodos de biomonitoramento da genotoxicidade mais utilizados atualmente estão o teste Allium cepa L. (cebola) (Scalon 2009).

A cebola é uma hortaliça condimentar bastante difundida no mundo, originaria provavelmente da Ásia Central, utilizada principalmente como especiaria para consumo humano a fins culinários. Pertencente à família das Liliáceas, gênero Allium, espécie $A$. серa L., é uma planta bianual, herbácea, folhas cerosas, raízes fasciculadas e atinge cerca de $60 \mathrm{~cm}$ (Muniz 2007).

O Allium cepa L. é um dos mais bem conhecidos e utilizados bioindicadores em estudos para deteç̧ão de contaminantes, e o mais sugerido como material teste padrão devido a sua sensibilidade, fácil manuseio, resultados rápidos e alta tolerância a diferentes condições de cultivo. Foi introduzido originalmente como organismo teste por Levan, em 1938 (Fiskesjö 1985).

O objetivo deste trabalho foi avaliar a qualidade ambiental de rios urbanos no município de Vassouras$\mathrm{RJ}$, através do teste da cebola (Allium cepa L.), exposta diretamente no leito dos rios.

\section{Material e Métodos}

A cidade de Vassouras, local de realização do experimento, localizada a $22^{\circ} 24^{\prime} 14^{\prime \prime} \mathrm{S}$ e $43^{\circ} 39^{\prime}$ $46^{\prime \prime} \mathrm{W}$, atualmente a cidade possui uma área territorial de $538,134 \mathrm{Km}^{2}$, com uma densidade demográfica de $63,94 \mathrm{hab} / \mathrm{Km}^{2}$ (IBGE 2010), localiza-se na região Sulfluminense do estado do Rio de Janeiro, e está inserida na bacia hidrográfica do Rio Paraíba do Sul. A cidade não possui qualquer sistema de tratamento de efluentes, que são despejados diretamente nos rios da região.

Para avaliar a qualidade da água dos rios, foi utilizado o teste da cebola (Allium cepa L.). Foram utilizados 60 bulbos de cebola com diâmetro aproximado de $40 \mathrm{~mm}$, obtidas de um produtor orgânico certificado pelo IBD (Instituto Brasileiro de Biodinâmica) sob o numero RJ 073, diminuindo o risco de contaminação das mesmas por outros agentes químicos e colhidas sempre no mesmo talhão (canteiro).

Previamente, as raízes primordiais dos bulbos foram removidas, e em seguida foram colocadas em bandejas com papel toalha umedecido com água destilada durante 24 horas, para atestar a viabilidade de crescimento das raízes. Foram selecionadas para o experimento apenas as que apontaram o crescimento de raízes.

Os rios que cruzam a cidade de Vassouras e que foram utilizados no experimento $\left(22^{\circ} 24^{\prime} 12.58^{\prime \prime} \mathrm{S}\right.$ e 4339'50.18”W) (Figura 1) são o Rio das Mortes (Ponto I), Rio Santa Catarina (Ponto II), Rio Bonito (Ponto III) e a dez metros à jusante do ponto de confluência dos rios (Ponto IV) (Figura 3). Como testemunha, foi utilizado 
um lago próximo a uma nascente (22 $22^{\prime} 54,32^{\prime \prime} \mathrm{S}$ e $43^{\circ} 38^{\prime} 07,48^{\prime \prime} \mathrm{W}$, Ponto V), livre de interferências antrópicas (Figuras 5, 6 e 7).

As cebolas foram distribuídas no delineamento de blocos ao acaso, com quatro tratamentos (rios) e uma testemunha (controle), todas com doze repetições, totalizando 60 bulbos $(\mathrm{N}=60)$, sendo expostas a condições naturais do ambiente.

Para cada tratamento foi feito sobre uma estrutura com bandeja de isopor de 200 células utilizadas para produção de mudas de hortaliças, medindo $60 \times 35 \times 2,5 \mathrm{~cm}$, que permite o experimento flutuar sobre a água, protegido na parte de cima com tela de viveiro contra folhas, galhos e animais, e a proteção para as raízes é de $15 \mathrm{~cm}$ de profundidade com estrutura de vergalhão 4.2 soldado e revestido com tela mosquiteiro branca, permitindo o livre crescimento das raízes (Figura 2). A estrutura foi fixada com arame galvanizado amarrado em bambu mirim estacado no fundo do rio.

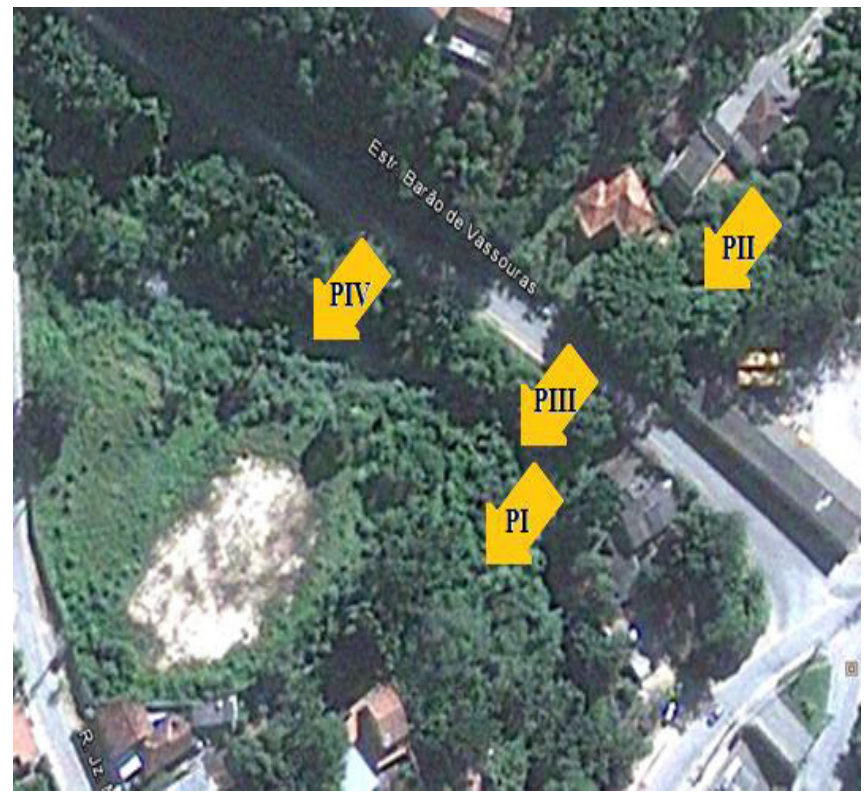

Figura 1. Fotografia aérea dos quatro pontos de montagem do experimento.

Fonte. Google Earth.

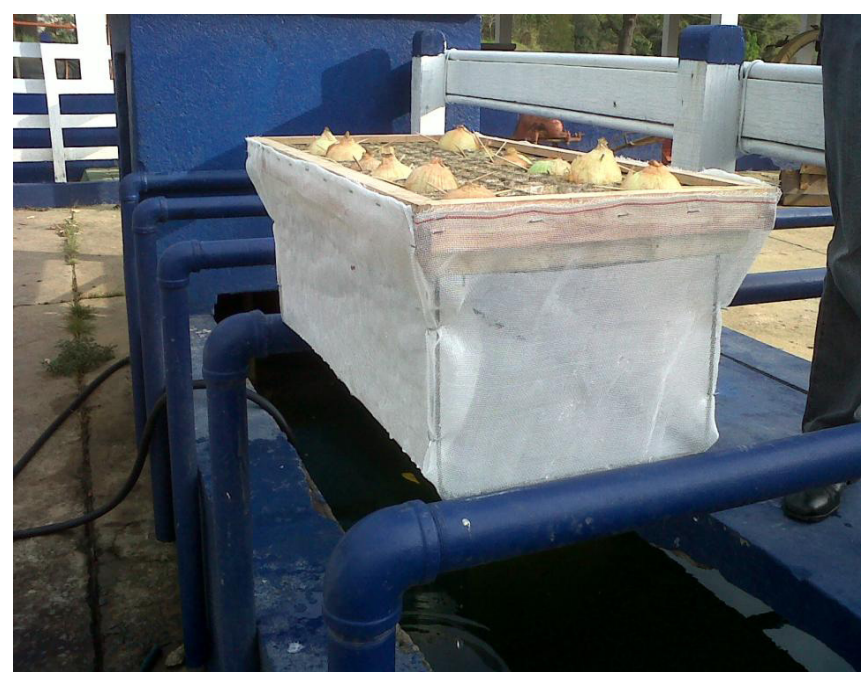

Figura 2. A estrutura com as cebola. Fonte. Nogueira, M. A.
Em cada bulbo foram inserido quatro palitos de madeira, levemente inclinados para sua fixação e estimulo ao enraizamento, em cada bandeja e imediatamente colocados diretamente dentro dos rios, com as raízes em contato com a água, nos pontos préestabelecidos, permanecendo no ambiente por sete dias, em condições naturais de luminosidade, temperatura e intempéries climáticos (Figura 3).

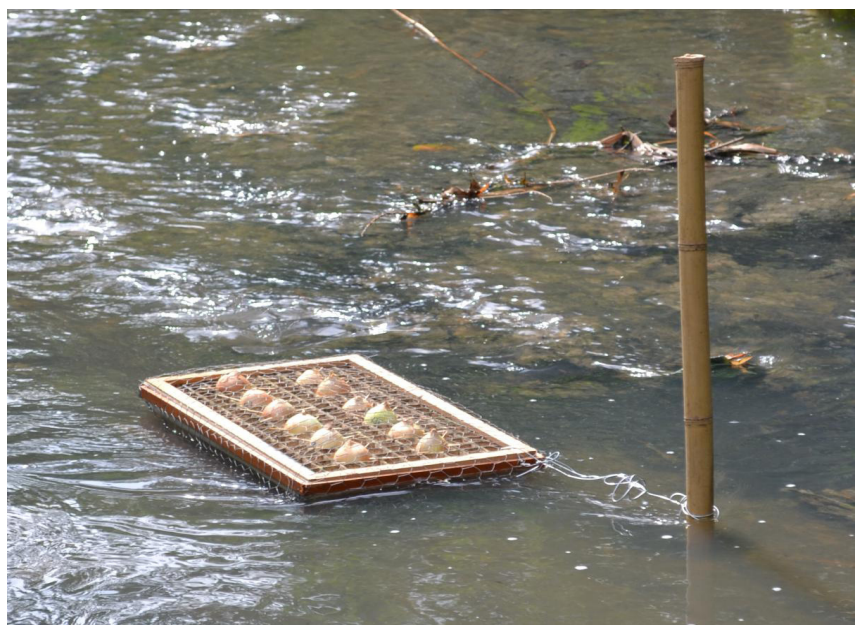

Figura 3. $\mathrm{O}$ experimento montado diretamente no leito do rio. Fonte. Duarte, M. N.

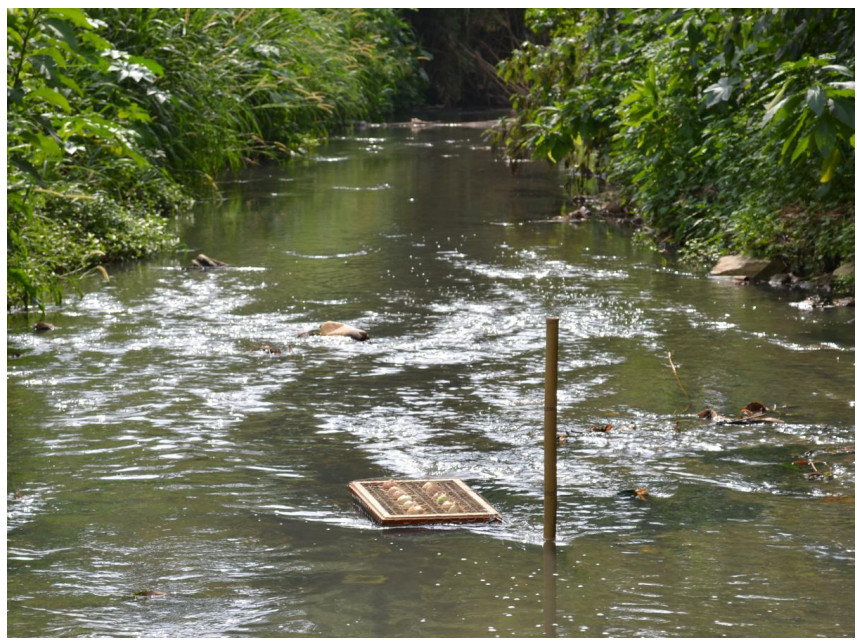

Figura 4. $\mathrm{O}$ experimento montado e as dimensões do rio após a confluência dos três rios. Fonte. Duarte, M. N.

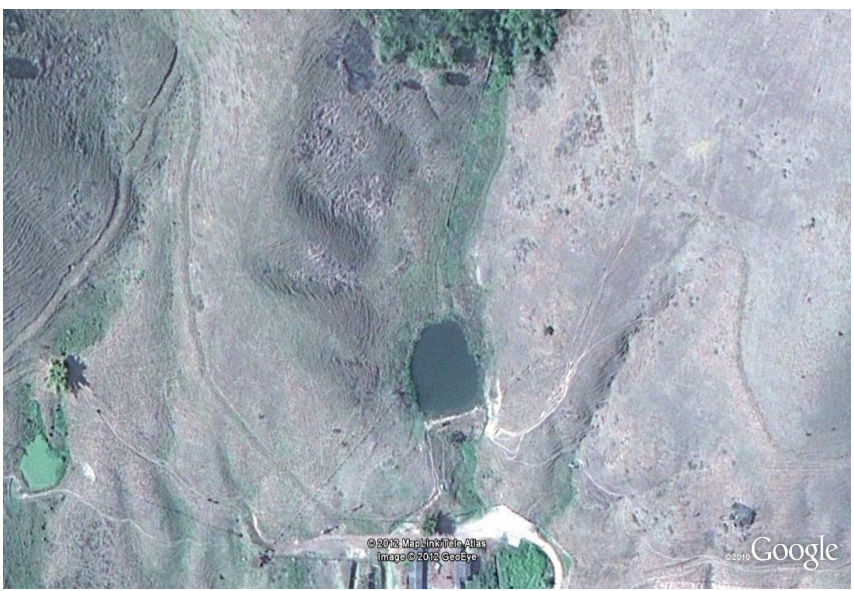

Figura 5. Vista aérea do lago utilizado como testemunha. Fonte. Google Earth 


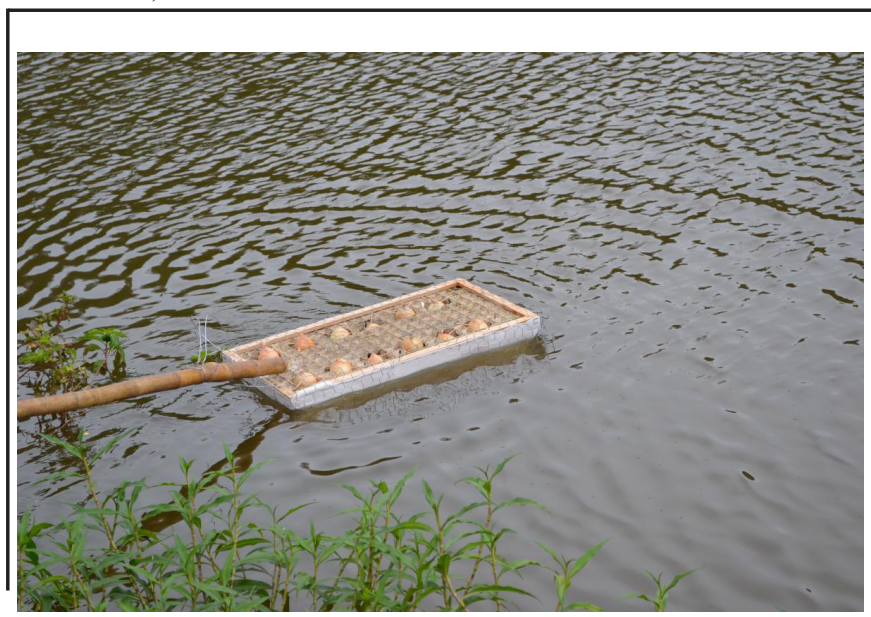

Figura 6. O experimento montado no lago (testemunha). Fonte. Duarte, M. N.

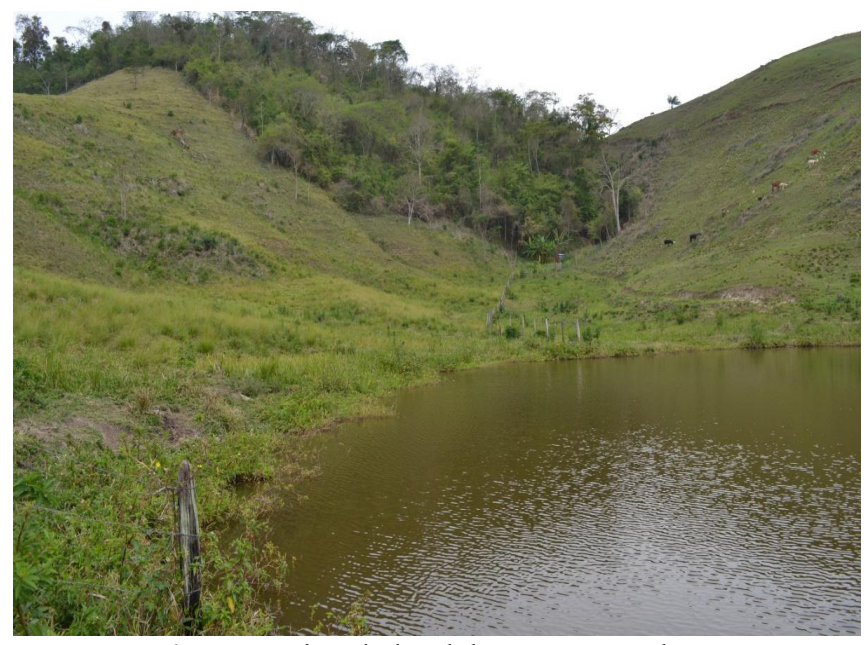

Figura 7. Vista do local da nascente e o lago. Fonte. Duarte, M. N.

Após a retirada do experimento, as raízes foram cortadas rente ao bulbo e contadas medidas por um paquímetro digital (Mitutoyo- precisão de $0,01 \mathrm{~mm}$ ) e pesadas por uma balança digital (precisão de $0,0001 \mathrm{~g}$ ).

Os dados foram submetidos à análise estatística onde comparou-se os dados dos rios com os dados da testemunha. As análises foram feitas em pares através do teste $\mathrm{t}$-student $(\mathrm{p}<0,05)$, dados pareados e independentes. Para verificar a normalidade dos dados utilizou-se o teste de Kolmogorov-Smirnov $(p<0,05)$, para cada tratamento.

\section{Resultados e Discussão}

Durante o período de sete dias do experimento, ocorreu uma enxurrada de grandes proporções e fez com que se perdessem os experimentos dos Pontos I, II e IV. Esse este foi um provável erro na metodologia, que foi não utilizar os principais veículos de comunicação para se informar sobre previsão do tempo ou retirar o experimento antes de enxurradas. Segundo Silveira (2004) os rios e riachos exibem características resultantes de seu papel como canais para o transporte do excesso de água, derivada da precipitação, que os ambientes terrestres não conseguem absorver.
Com isso, restaram-se apenas os experimentos da testemunha (Ponto V) e do Ponto III, reduzindo o tamanho da amostra de $\mathrm{N}=60$ para $\mathrm{N}=24$, o que é considerado ideal (Nideal $=24)$. Apesar disso, obtiveram-se dados relevantes a respeito do estado do Rio Bonito em relação à testemunha, tanto na massa das raízes quanto no comprimento.

No Ponto III $(1,53 \mathrm{~mm} \pm 1,94)$ obteve diferença estatística significativa em relação à testemunha $(24,98 \mathrm{~mm} \pm 13,28)$ quando se analisa o comprimento das raízes $(\mathrm{T}=20,82 * *$ à $5 \%$ de probabilidade) (Figura 4). Quanto ao número de raízes, o Ponto III obteve 86 raízes, enquanto a testemunha obteve 138 raízes. No Ponto III ocorreu falha no enraizamento em 41,67\% das cebolas, enquanto na testemunha ocorreu taxa de enraizamento de $100 \%$.

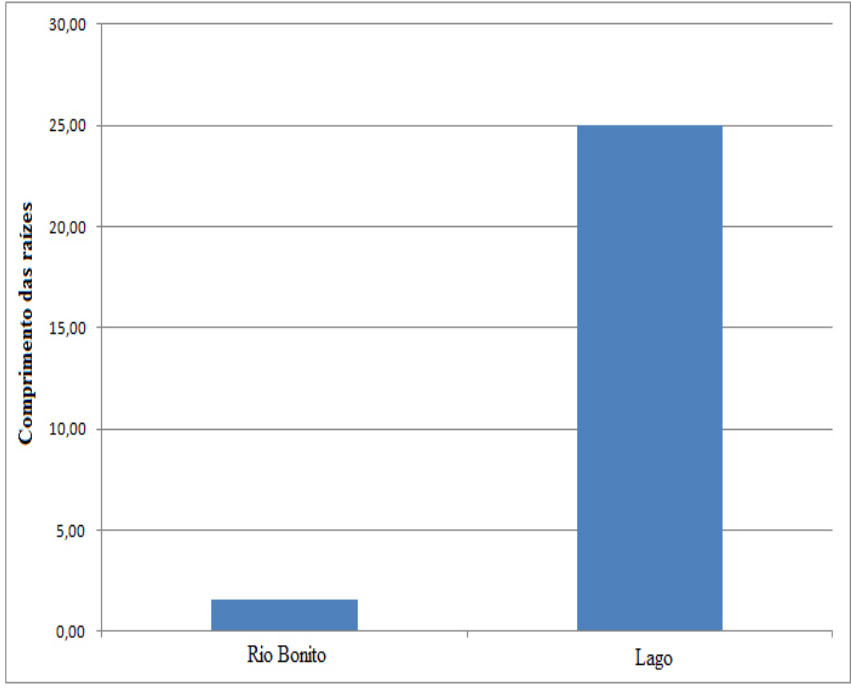

Figura 4. Comprimento das raízes submetidas ao teste, sendo o Rio Bonito (Ponto III) o tratamento e o Lago (Ponto V) a testemunha.

Quanto à massa das raízes, a diferença foi estatisticamente significativa entre o Ponto III $(1,53 \mathrm{~g} \pm$ $0,0202)$ e a testemunha $(0,1616 \mathrm{~g} \pm 0,1659)$, apresentando $\mathrm{T}=8,58 * *$ à $5 \%$ de probabilidade (Figura 5 ).

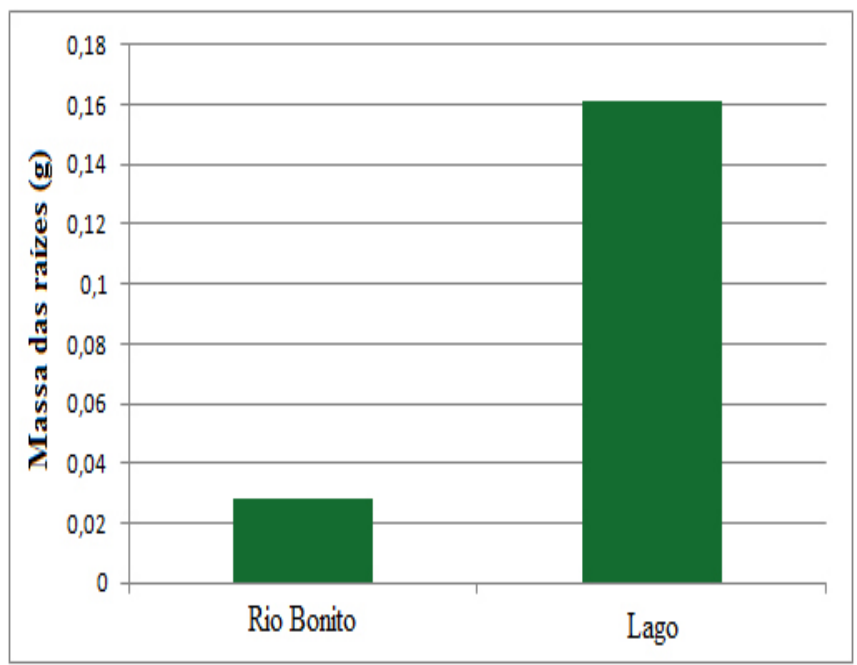

Figura 5. Massa das raízes submetidas ao teste, sendo o Rio Bonito (Ponto III) o tratamento e o Lago (Ponto V) a testemunha. 
Gonçalves et al. (2011), em estudo com rios urbanos do município de Vassouras-RJ, utilizando ensaios em laboratório com as cebolas, e obtiveram diferença estatística significativa entre os tratamentos, tanto no comprimento quanto na massa, onde a testemunha (Água tratada) foi a que apresentou maior taxa de crescimento.

Segundo Von Sperling (2005), mesmo com as bacias hidrográficas preservadas e nas condições naturais, a qualidade da água é afetada pelo escoamento superficial e pela infiltração no solo, resultante das precipitações atmosféricas.

Sendo assim, mesmo havendo alterações de padrão natural devido à chuva, ou seja, o padrão de potabilidade da água variável, pode-se avaliar o que ocorreria normalmente com as raízes, diferentemente do que seria criando condições semelhantes em laboratório, onde o padrão de potabilidade seria constante.

Segundo Schiavini et al. (2011), os bioindicadores podem ser divididos em dois grupos: de acumulação e de reação. Desta forma, temos os organismos testes, ou seja, são submetidos a ensaios em laboratórios, o que leva a ser bioindicadores ativos, uma vez que há ação e reação direta, por causa e efeito, sem a interferência de atenuadores naturais. Existem também os apontadores, estes permite uma maior precisão das suas respostas, uma vez que haverá interferências dos atenuadores naturais (Schiavini et al., 2011).

Segundo Brito-Pelegrini et al. (2007), substâncias químicas como metais pesados, compostos orgânicos, nitrogênio e organo-halogenados, em altas concentrações, contribuem para a extrema elevação dos nível de toxicidade em quaisquer ambientes. Estes autores utilizaram o teste da cebola em líquidos percolados de aterros sanitários, para detecção de toxicidade aguda destes compostos.

\section{Conclusões}

Após o experimento, verificou-se que é valida a realização do teste da cebola, dispondo-as diretamente no leito de rios, gerando resultados que corroboram os estudos de outros autores com ensaios em laboratório.

Entretanto, um possível erro na metodologia aplicada neste trabalho pode ter resultado na perda de parte dos experimentos, depois da enxurrada. Uma mudança na metodologia seria a verificação da previsão do tempo. Outra proposta pode ser a verificação diária dos experimentos. Quando possível, remover temporariamente antes que ocorra a enxurrada.

Outra solução poderia ser o modo de fixação dos experimentos, ao invés de fixar no fundo do rio, fixar nos barrancos, levando em consideração que o experimento do Ponto III foi preso justamente no barranco.

Apesar do erro no experimento, os resultados mostraram o claro estado de saúde do rio Bonito, onde a diferença no crescimento das raízes pode apontar a existência de compostos químicos genotóxicos na água deste rio e que inibiram o crescimento normal das raízes.

\section{Referências}

Barbério, A.; Barros, L.; Voltolini, J. C. and Mello, M. L. S. (2009). Evaluation of the cytotoxic and genotoxic potential of water from the River Paraíba do Sul, in Brazil, with the Allium cepa L. test. UNICAMP/UNITAU, Braz. J. Biol., 69(3): 837-842 In.

Barbério, A. (2008). Efeitos Citotóxicos e Genotóxicos no Meristema Radicular de Allium cepa exposta à Água do Rio Paraíba do Sul - Estado de São Paulo - Regiões de Tremembé e Aparecida. Dissertação (Doutorado) - Curso de Ciências Biológicas, Departamento de Instituto de Biologia, Universidade Federal de Campinas, Campinas-SP, 85 p..

Bollmann, H. A. e Edwiges, T. (2008). Avaliação da qualidade das águas do Rio Belém, Curitiba-PR, com o emprego de indicadores quantitativos e perceptivos. Engenharia Sanitária e Ambiental. v. 13, nº 4. p. 443-452.

Braga, B.; Hespanhol, I.; Conejo, J.G. L.; Barros, M,T.; Spencer, M.; Porto, M.; Nucci, N.; Juliano, N. e Eiger, S. (2002). Introdução à Engenharia Ambiental. São Paulo: Prentice Hall.

Brasil (2006). Vigilância e controle da qualidade da água para consumo humano/ Ministério da Saúde, Secretaria de Vigilância em Saúde. Ministério da Saúde. Secretaria de Vigilância em Saúde. Brasília-DF.

Brito-Pelegrini, N. N.; Pelegrini, R. T. e Paterniani, J. E. S. (2007). Ecotoxicological evaluation of leachate from the Limeira sanitary landfill with a view to identifying acute toxicity. UNICAMP-FEAGRI, Revista Ambiente \& Água, v. 2, n. 3. Campinas-SP

CONAMA. Conselho Nacional do Meio Ambiente (2005). Resolução Normativa No 357 de 17 de Março de 2005.

Fiskesjö, G. (1985). The Allium test as a standard in environmental monitoring. Hereditas, Lundskrona, p. 99-112.

Giordano, G. (2004). Tratamentos e Controle de Efluentes Industriais. Enderenço: http://www.cepuerj.uerj.br, Maio. Acesso em: 24/11/2012.

Gonçalves, P. S.; Oliveira, C. S. P.; Ribeiro, S. V.; Santos, H. F. e Rodrigues, W.C. (2011). Avaliação da qualidade de rios urbanos, no município de Vassouras, através do teste da cebola (Allium cepa L.). Universidade Severino Sombra, X Congresso de Ecologia do Brasil - 2011, São Lourenço-MG.

IBGE (2010). Disponível em http://www.ibge.com.br/cidadesat/topwindow. htm?1. Acesso em 19/11/2012.

Levan, A. (1938). The effect of colchicine on root mitoses in Allium. Hereditas 24: 471-486.

Merten, G. H. e Minella, J. P. (2002). Qualidade da água em bacias hidrográficas rurais: um desafio atual para a sobrevivência futura Agroecol. e Desenvol. Rur. Sustent. Porto Alegre, v.3, n.4.

Muniz, L. B. (2007). Caracterização química, física e de compostos funcionais em cebolas frescas minimamente processadas. Dissertação de Mestrado. UnB. Departamento de Nutrição. Programa de Pós-Graduação em Nutrição Humana. Distrito Federal - Brasil. 160p.

Scalon, M. C. S. (2009). Avaliação dos efeitos genotóxicos da água do Rio dos Sinos sobre peixes e vegetais. Dissertação de Mestrado. Centro Universitário Feevale. Programa de Pós-Graduação em Qualidade Ambiental. Novo Hamburgo-RS. 68 p.

Schiavini, J. A.; Cardoso, C. E. e Rodrigues, W.C. (2011). Desreguladores Endócrinos no Meio Ambiente e o Uso de Potenciais Bioindicadores. Revista Eletrônica TECCEN, Vassouras, v. 4, n. 3, p. 33-48.

Silveira, M. P. (2004). Aplicação do biomonitoramento para avaliação da qualidade da água em rios, Documentos 36. Embrapa, Jaguariúna. 68 p. 
Valença, J. F. S. (2003). Rio Salgado: agente de agravos à saúde das populações ribeirinhas. Dissertação de Mestrado: UESC/ PRODEMA. 116 p.

Von Sperling, M. (2005). Introdução à qualidade das águas e ao tratamento de esgotos. Universidade Federal de Minas Gerais. $3^{\text {a }}$ Edição. 